\title{
A Novel Method to Measure the Steady State Torque of Permanent Magnet Hybrid Stepper Motor Using DSP Controller
}

\author{
E.V.C Sekhara Rao ${ }^{1}$, P.V.N.Prasad ${ }^{2}$ \\ ${ }^{1}$ (Department of EEE, CBIT, Osmania University, India) \\ ${ }^{2}$ (Department of EE, UCE, Osmania University, India)
}

\begin{abstract}
This paper discusses about a novel approach to measure steady state torque of permanent magnet hybrid (PMH) stepper motor using DSP processor without using any sensors. The voltage wave form of each phase is investigated in this paper. This measured torque is compared with theoretical calculated torque from the given data of motor.
\end{abstract}

Keywords - PMH stepper motor, steady state torque, DSP processor

\section{Introduction}

Stepper motor is a special electric motor whose torque is discrete in nature [1].Stepper motors are classified into two categories as permanent magnet motors and variable reluctance motor based on its rotor. Combination of these two types is considered as permanent magnet hybrid stepper motor (PMH).PMH stepper motor has wide applications like solar array tracking system, space crafts and robotics [2]. The salient feature of PMH stepper motor is very low stepping angle, good steady state and dynamic responses [3, 4]. PMH motor steady state torque is measured through sensors experimentally [5]. In this paper a new method is proposed to measure steady state torque of PMH stepper motor experimentally without using any sensors.

\section{PMH STEPPER MOTOR}

The practical PMH stepper motor operates in the same way as the simple model shown in Fig.1 [6]. A larger number of teeth on the stator and gives a smaller basic step size. The stator has a two-phase winding. Each phase winding consists of two sections. The stator shown in Fig. 1 has 8 poles each with 5 teeth, making a total of 40 teeth. If a tooth is placed in each of the zones between the stator poles, there would be a total of 48 teeth.The rotor consists of an axially magnetized PM located between two ferromagnetic disks with 50 teeth per disk, two more than the number of uniformly distributed stator teeth.

There is a half-tooth displacement between the two sections of the rotor. If rotor and stator teeth are aligned at 12 o'clock, they will also be aligned at 6 o'clock. At 3 o'clock and 9 o'clock the teeth will be misaligned. However, due to the displacement between the sets of rotor teeth, alignment will occur at $\mathbf{3}$ o'clock and 9 o'clock at the other end of the rotor. The windings are arranged in sets of four, and wound such that diametrically opposite poles are the same. The north poles at 12 o'clock and 6 o'clock attract the south-pole teeth at the front of the rotor; the South poles at 3 o'clock and 9 o'clock attract the North-pole teeth at the back.

By switching current to the second set of coils, the stator field pattern rotates through $45^{\circ}$ but to align with this new field the rotor only has to turn through $1.8^{0}$. This is equivalent to one quarter of a tooth pitch or $7.2^{0}$ on the rotor, giving 200 full steps per revolution.

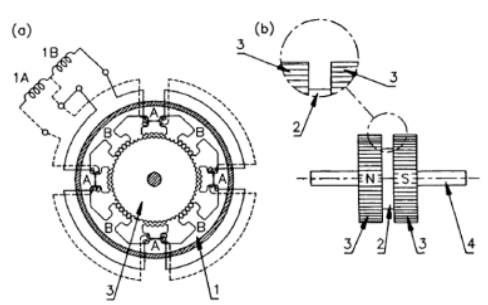

Fig.1. Hybrid stepping motor performing 200 steps per revolution :( a) cross section, (b) rotor. 1 -stator core, 2 PM, 3 - ferromagnetic disk with teeth, 4 - shaft.

III. STEady State Torque

Static torque of $\mathrm{PMH}$ motor for single phase energisation is vitally related to the permeance variation with respect to the rotor position and is given by $T=\frac{\mathbb{N}_{\mathrm{K}}}{2}(\mathrm{NI})\left(\mathrm{B}_{0} \mathrm{~A}_{\mathrm{m}}\right)\left(\frac{\underline{p}_{\mathrm{P}_{0}}}{\mathbf{p}_{0}}\right)\left(\sin \left(\theta_{\mathrm{e}}\right)\right)$ 
Where $\mathrm{N}_{\mathrm{R}}$ is rotor teeth, $\mathrm{N}$ is turns per coil per phase, I is per phase current in A, B0 is flux density of permanent magnet in $\mathrm{Wb} / \mathrm{m}^{2}, A m$ is area of permanent magnet in $\mathrm{m}^{2}$, and $\rho_{0}, \rho_{1}$ are Fourier coefficients and $\theta_{\mathrm{e}}$ is electrical angle in degrees.

\section{Novel Method to Measure Steady-State Torque of PMH Stepper Motor}

A proto type PMH stepper motor data is given in Table 1. Two such identical motors are coupled using a low weight coupling process as shown in Fig.2. One of the motors is driven as motor with DSP processor. Other motor is considered as generator. One of the motors is driven using DSP processor at different speeds by changing time constants of processor. Corresponding induced voltages in the other machine are noted at no-load and shown in Table 2. Fig. 3 shows linear relation between speed and induced voltage.

Table 1 Data of PMH stepper motor

\begin{tabular}{|c|c|c|c|c|}
\hline Stator poles & $\begin{array}{c}\text { Tooth per } \\
\text { stator pole }\end{array}$ & $\begin{array}{c}\text { Outer } \\
\text { diameter of } \\
\text { stator }\end{array}$ & $\begin{array}{c}\text { Inner } \\
\text { diameter of } \\
\text { stator }\end{array}$ & $\begin{array}{c}\text { Outer } \\
\text { diameter of } \\
\text { stator shell }\end{array}$ \\
\hline 4 & 8 & $10.108 \mathrm{~cm}$ & $5.936 \mathrm{~cm}$ & $10.652 \mathrm{~cm}$ \\
\hline $\begin{array}{c}\text { number of } \\
\text { rotor Teeth }\end{array}$ & $\begin{array}{c}\text { Number of } \\
\text { turns per } \\
\text { phase }\end{array}$ & $\begin{array}{c}\text { Section } \\
\text { length of } \\
\text { rotor }\end{array}$ & $\begin{array}{c}\text { Outer } \\
\text { diameter of } \\
\text { rotor }\end{array}$ & $\begin{array}{c}\text { Inner diameter } \\
\text { of rotor }\end{array}$ \\
\hline 50 & 46 & $10.26 \mathrm{~cm}$ & $4.2 \mathrm{~cm}$ & $1.74 \mathrm{~cm}$ \\
\hline $\begin{array}{c}\text { No of turns } \\
\text { per stator } \\
\text { pole }\end{array}$ & Rated & $\begin{array}{c}\text { Rated } \\
\text { current }\end{array}$ & $\begin{array}{c}\text { SWG of } \\
\text { conductor }\end{array}$ & Torque \\
\hline 92 & $12 \mathrm{~V}$ & $1 \mathrm{~A}$ & 36 & $1.5 \mathrm{Nm}$ \\
\hline
\end{tabular}

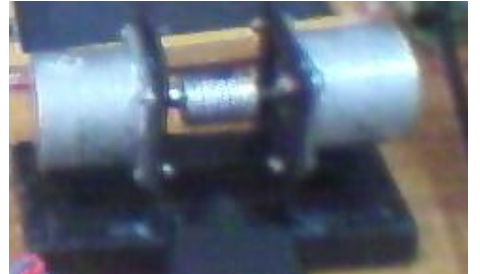

Fig.2. Proto type PMH Stepper motor generator set

Table 2 Speed Vs No-load voltage

\begin{tabular}{|c|c|c|c|c|c|}
\hline Speed, rad/s & 01 & 05 & 10 & 20 & 30 \\
\hline $\begin{array}{c}\text { Induced } \\
\text { voltage, V }\end{array}$ & 1.5 & 7.8 & 15.6 & 29 & 43 \\
\hline
\end{tabular}

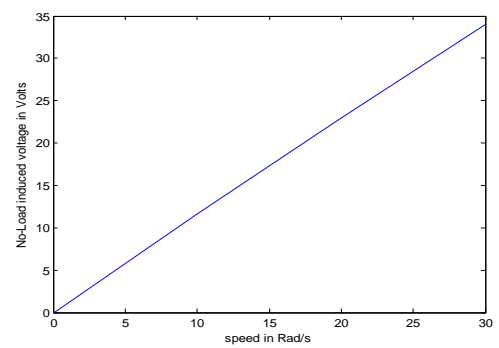

Fig.3. Speed Vs No-load Voltage

A potential resistive load is connected to generator mode machine terminals. Speed of the motor is noted down at different load currents of generator and shown in Table 3. The relation of drooping between load current and speed is shown in Fig.4. 
Table 3 Load current Vs Speed

\begin{tabular}{|c|c|c|c|c|}
\hline Current, A & 0.2 & 0.5 & 1 & 1.5 \\
\hline Speed, $\mathrm{rad} / \mathrm{s}$ & 30 & 29 & 28 & 27 \\
\hline
\end{tabular}

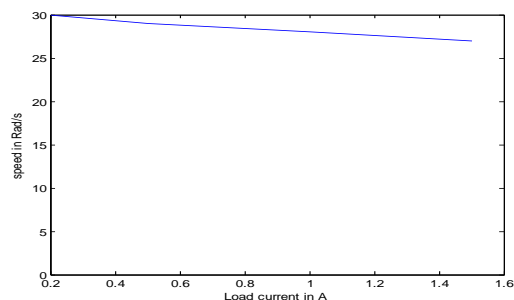

Fig.4. Load current Vs Speed

From the results of no-load and load tests on $\mathrm{PMH}$ stepper motor-generator set, rated torque is calculated. Speed corresponding to rated current $1 \mathrm{~A}$ is obtained as $28 \mathrm{rad} / \mathrm{s}$ from load characteristic. Induced voltage corresponding to $28 \mathrm{rad} / \mathrm{s}$ is obtained as $28.5 \mathrm{~V}$ from no-load characteristic. Product of no-load voltage and load current of PMH generator is considered as electrical output of PMH stepper motor. Torque of PMH stepper motor is obtained dividing this product with corresponding angular speed $28 \mathrm{rad} / \mathrm{s}$. The corresponding toque calculated is equal to $1.1 \mathrm{Nm}$. The same procedure is repeated at $1.5 \mathrm{~A}$ and torque calculated is equal to $1.51 \mathrm{Nm}$.

\section{CONCLUSION}

Steady-state torque of PMH stepper motor is measured experimentally in a novel method. At rated current steady-state torque is less than rated value due to high detent torque. For rated steady-state torque motor drew more than rated current. To obtain rated steady-state torque at rated current detent torque is to be reduced.

\section{REFERENCES}

[1] H. D. Chai, A Mathematical Model for Single-Stack Step Motors, IEEE Transactions on PowerApparatus and Systems, Vol. PAS94, no. 5, September/October 1975.

[2] K. R. Rajagopal, M. Krishnaswammy, Bhim Singh and B. P. Singh, An Improved High- Resolution Hybrid Stepper Motor for SolarArray Drive of Indian Remote- Sensing Satellite', IEEE Transactions on Industry Applications, Vol. 33,No. 4, July/August 1997

[3] E.V.C.Sekhara Rao, P.V.N.Prasad, Comparative study of laminated core PMH motor with SMC claw pole motor,' IEEE internationa conference PEDES06,IIT, Delhi, December 2006.

[4] E.V.C.Sekhara Rao, P.V.N.Prasad, Mid Frequency Response on Dynamic Behavior of PM stepper Motor, IET-UK Internationa Conference on Information and Communication Technology in Electrical Sciences (ICTES 2007), Tamil Nadu, India, 20 - 22 Dec. 2007.

[5] Praveen R.P, Ravichandran M.H, V. T. Sadas Achari, Dr.Jagathy Raj V. P, Dr.G.Madhu and Dr.G.R. Bindu, Design and Finite Eleme Analysis of Hybrid Stepper Motor for Spacecraft Applications, IEEE transactions on Magnetics, Vol.45, No. 4, July/August. 2009

[6] Jacek F. Gieras, Mitchell Wing, Permane Magnet Motor Technology Design and Applications, ISBN: 0-8247-0739-1, Marcel Dckker Inc, New York, USA. 